\title{
Physical and Technical Aspects of Measurements of Ordinary and Extraordinary Refraction Indices and Birefringence of Nematic Liquid Crystals
}

\author{
J. KęDZIERski ${ }^{a}$, M.A. Kojdecki ${ }^{b, *}$, K. Kowiorski ${ }^{c}$, Z. RASzewski ${ }^{a}$ And E. MiszczyK ${ }^{d}$ \\ ${ }^{a}$ Institute of Applied Physics, Military University of Technology, Warsaw, Poland \\ ${ }^{b}$ Institute of Mathematics and Cryptology, Military University of Technology, Warsaw, Poland \\ ${ }^{c}$ Institute of Electronic Materials Technology, Department of Chemical Technologies, Warsaw, Poland \\ ${ }^{d}$ Institute of Physics, University of Technology and Humanities, Radom, Poland \\ (Received April 1, 2019; revised version April 23, 2019; in final form April 27, 2019)
}

\begin{abstract}
This article is a survey of techniques for experimental determination of ordinary and extraordinary refractive indices and birefringence of uniaxial liquid crystals. The ideas of methods are briefly described with basic references added.
\end{abstract}

DOI: 10.12693/APhysPolA.136.196

PACS/topics: liquid crystals, refractive indices of liquid crystals, wedge cell, birefringence, interference, measurements of refractive indices

\section{Liquid crystals as optical media}

Liquid crystals are birefringent liquids in which refractive index depends on orientation of electric vector of light wave with respect to optical axis of ordered liquid. Such anisotropy distinguishes them from liquids where birefringence can be enforced only by external fields $[1,2]$.

When a thin film of planar-oriented liquid crystal confined between two parallel plane glass plates is placed between crossed polarisers, initially dark view field becomes brighter. The brightness is maximal when the angles between direction of nematic molecules and polariser transmission axes are half-right and minimal when they are zero and right. For a nematic of homeotropic orientation the view field remains dark irrespective of rotations of the plate. A plane-parallel layer of liquid crystal features optical properties like a plate cut of uniaxial crystal. The optical axis is always parallel to director of nematic [1]. Refractive index for a polarised light-beam with electric vector parallel to optical axis is called index of refraction of extraordinary rays or simply extraordinary refractive index $\left(n_{e}\right)$ and similarly, for a beam with electric vector perpendicular to optical axis, is called index of refraction of ordinary rays or ordinary refractive index $\left(n_{o}\right)[3,4]$.

\section{Experimental methods}

for determining refractive indices and birefringence of liquid crystals

Since a sample of ordered nematic liquid crystal or smectic liquid crystal features optical properties of

*corresponding author; e-mail: Marek.Kojdecki@wat.edu.pl an uniaxial solid crystal, the same methods can be applied for determining refractive indices $n_{e}, n_{o}, n_{i}$ (for isotropic state at higher temperature) and birefringence $\Delta n \equiv n_{e}-n_{o}$ (as described in e.g. [5-7]). All these methods can be divided into two classes: (1) goniometric (or spectrometric), including (1a) refractometric or (1b) prismatic and (2) interferometric ones.

\section{1. (1a) Refractometric methods}

Refractometric methods involve measurements of critical angle of refraction (or minimal angle of total internal reflection) [8] using Abbe's or Pulfrich's refractometer being in fact specific goniometers with short measuring bars. The idea of refractometric measurements is presented in Fig. 1.

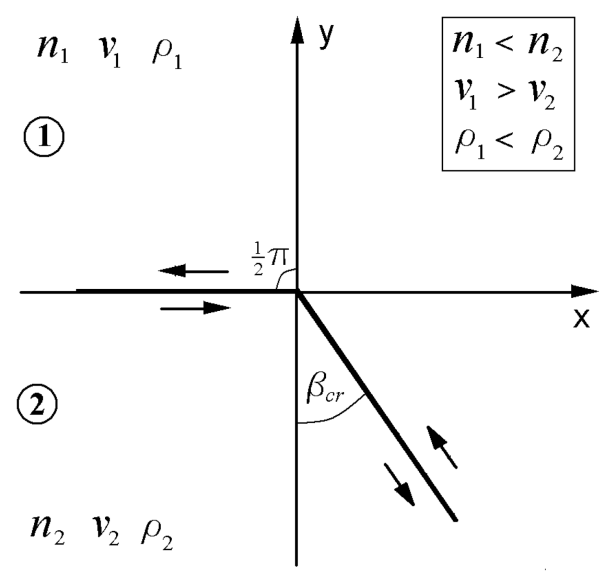

Fig. 1. Transmission of light from a less dense medium 1 to a more dense medium 2 or from 2 to 1 through a plane boundary: $n_{1}, n_{2}$ - refractive indices, $v_{1}, v_{2}$ light speeds, $\rho_{1}, \rho_{2}$ - specific masses, $\beta_{c r}$ - critical angle of refraction or total internal reflection; $n_{1} v_{1}=$ $n_{2} v_{2}=c$ - light speed in vacuum. 
The measurements can be performed in transmitted light when rays pass from less dense medium 1 to more dense medium 2 or in reflected light when rays pass from 2 to 1 . In the first variant the largest possible angle of refraction $\beta_{c r}$ is determined when rays begin to slide along the limit boundary while in the second variant the smallest possible angle of total internal reflection $\beta_{c r}$ is determined when rays begin to return from the boundary. Usually Abbe's cube is made of two rectangular prisms admitting mutual rotations. An investigated specimen is placed as thin layer between specially prepared prism walls $[8,9]$. Then the cube is put into goniometer which constitutes Abbe's refractometer [10, 11]. Dorn [12] and Pelzl and Sackmann [13] applied Abbe's cube for the first time to measure refractive indices of liquid crystals. In Abbe's cube a liquid crystal is oriented homogeneously - with optical axis parallel to surface of refraction of prisms and perpendicular to plane of incidence of light (a sample with homeotropic order can also be used). This method is useful but with significant constraints. A measured refractive index is bounded by the refractive index of material the prisms are made of. A standard bound is 1.7 while for nematic liquid crystals often $n_{e}>1.7$. The production of prisms with refractive index larger than 1.7 (up to 1.87) is possible but such special glasses with $n>1.7$ are soft, weak, expensive, and difficult to be managed. Absolute inaccuracy in determining $n_{e}$ and $n_{o}$ is around $\pm(0.05 \div 1.0) \times 10^{-3}$ and even worse frequently since especially for multi-compound liquid crystals the limit line in the image is blurred. The texture of studied nematic layer is not visible. Many authors [10, 14-25] applied this method for determining $n_{e}, n_{o}, n_{i}$. Abbe's refractometer can be replaced by Pulfrich's refractometer based on similar concept. A sample of liquid crystal can be too a plane-parallel layer with homogeneous (planar) or homemotropic order but only transmission mode in monochromatic light can be exploited.

\section{2. (1b) Prismatic methods}

Prismatic methods involve observation of deviation of rays passing through a prism filled with sample of ordered liquid crystal (Fig. 2).

A prismatic sample of nematic liquid crystal is placed in goniometer or refractometer with edge walls parallel to rotation axis of lens. An image is observed through lens and the smallest angle of deviation for rays passing through prism perpendicular to optical axis is measured $[26,5,7]$. Two such images are found, since the sample is birefringent [5], for ordinary and for extraordinary rays and serve to computing refractive indices. Usually incident rays passing perpendicularly through one of wedge sample walls are used. Chatelain measured $n_{e}$ and $n_{o}$ of PAA $[27,28]$ for the first time using this method (with apex angle of $9^{\circ}$ and ray deviation between $5^{\circ}$ and $8^{\circ}$ ), therefore it is often called method of Chatelain's wedge [29]. Afterward many similar measurements were realised (Brunet-Germain, Pellet,

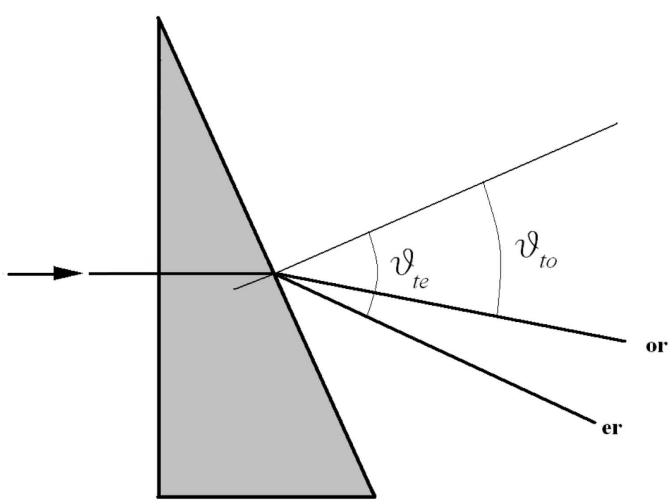

Fig. 2. Scheme of rays passing through a wedge-like homogeneous sample of liquid crystal. The optical axis is parallel to refractive surfaces of prism and perpendicular to plane of incidence (i.e. plane of diagram).

Chatelain [30-33]). Absolute inaccuracy in determining $n_{e}$ and $n_{o}$ is around $\pm(1 \div 5) \times 10^{-3}$. The advantages of this method are absence of bound for measured refractive index [34-39] and easiness of determining dispersive characteristics. The disadvantages are difficulty in thermal stabilisation of the prism and invisibility of texture of nematic liquid crystal during measurements.

\section{3. (2) Interferometric methods}

Interferometric methods are based on interference of linearly polarised light travelling through birefringent medium and exploiting linear or circular polariscope [4042] as sketched in Fig. 3.

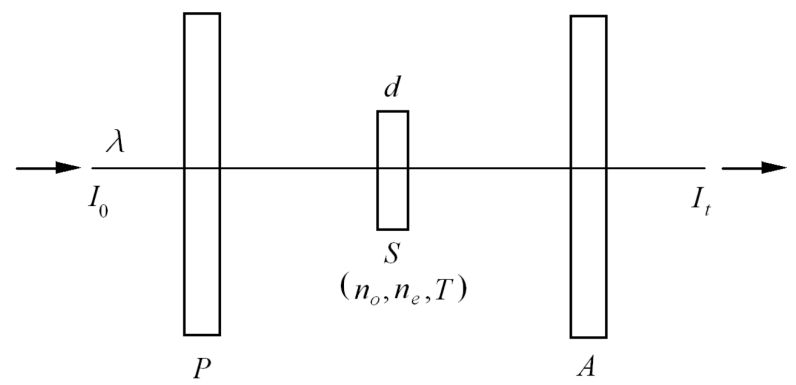

Fig. 3. Scheme of a polariscope: $P-$ polariser, $S$ - birefringent sample, $A$ - analyser, $\Delta n$ - birefringence, $d$ - thickness of sample, $\lambda$ - wavelength of monochromatic light, $k$ - natural number, $T$ - sample temperature [41-43]. The intensity of light passing through a polariscope is recorded by a photodetector, $I=f(d, \Delta n, \lambda, T, k) ;$ minima of intensity correspond to differences of optical paths $d \Delta n=k \lambda$.

The transmission of a linear polariscope follows formula [43-46]:

$$
\begin{aligned}
I & =2 I_{0} \tau^{2}\left(\cos ^{2}\left(\vartheta_{P}-\vartheta_{A}\right)\right. \\
& \left.-\sin \left(2 \vartheta_{P}\right) \sin \left(2 \vartheta_{A}\right) \sin ^{2} \frac{\pi d \Delta n}{\lambda}\right),
\end{aligned}
$$


where $\lambda, I_{0}$ are wavelength and intensity of non-polarised monochromatic light incident on a polariscope, respectively, $\tau=\frac{1}{2}$ is amplitude transmittance of an ideal polariser or analyser, $I$ is intensity of light leaving polariscope, $\vartheta_{P}=\angle\left(\boldsymbol{n}, \boldsymbol{w}_{P}\right), \vartheta_{A}=\angle\left(\boldsymbol{n}, \boldsymbol{w}_{A}\right)$ are angles between axes of transmission of polariser and analyser (angles $\vartheta_{P}, \vartheta_{A}, \vartheta$ are measured in plane of principal section of liquid crystal cell or birefringent plate cut from uniaxial solid crystal), $\boldsymbol{w}_{P}$ is vector of the transmission axis of a polariser, $\boldsymbol{w}_{A}$ is vector of the transmission axis of an analyser, $\boldsymbol{n}$ is director of a nematic liquid crystal in a planar cell placed in linear polariscope, $\Delta n$ is birefringence, and $d$ is thickness of sample.

The interference with maximal birefringent contrast appears in two cases [45]:

(i) when $\vartheta_{P}=\vartheta_{A}=45^{\circ}, \boldsymbol{w}_{A} \| \boldsymbol{w}_{P}$ and (1) reduces to

$$
I=2 I_{0} \tau^{2} \cos ^{2} \frac{\pi d \Delta n}{\lambda}=I_{\max } \cos ^{2} \frac{\pi d \Delta n}{\lambda},
$$

where $I_{\max }=2 I_{0} \tau^{2}$ is maximal intensity of light transmitted through mutually parallel polariser and analyser in empty polariscope;

(ii) when $\vartheta_{P}=+45^{\circ}, \vartheta_{A}=-45^{\circ}$ or $\vartheta_{P}=-45^{\circ}$, $\vartheta_{A}=+45^{\circ}, \boldsymbol{w}_{A} \perp \boldsymbol{w}_{P}$ and (1) reduces to

$$
I=2 I_{0} \tau^{2} \sin ^{2} \frac{\pi d \Delta n}{\lambda}=I_{\max } \sin ^{2} \frac{\pi d \Delta n}{\lambda}
$$

and light passes through mutually perpendicular polariser and analyser. Minima of transmission appear for

$$
d \Delta n=k \lambda \text {. }
$$

This variant is especially useful in laboratory measurements.

In all interferometric methods parallel linearly polarised light beam passes through birefringent sample. The interference image observed on leaving analyser depend on: shape of sample (being plane-parallel or wedgelike), spectral composition of incident light, angle between plane of polarisation of incident light and optical axis of sample, and angle between planes of polarisations of polariser and analyser. As it follows from formula (1) $I=f(d, \lambda, T)$ when $\vartheta_{P}, \vartheta_{A}, \Delta n$ are fixed. The intensity of transmitted light can be measured in the polariscope as a function of each of these three experimental parameters.

(a) $I=f_{1}(T)$ with $d, \lambda$ fixed and continuous quasistatic change of temperature. Such measurements can be called variable temperature interferometry (VTI).

(b) $I=f_{2}(\lambda)$ with $d$, $T$ fixed. The liquid crystal cell must be plane-parallel being in fact a Fabry-Perot interferometer. The interference field is homogeneous for normally incident parallel light beam. Such measurements can be called variable wavelength interferometry (VWI).

(c) $I=f_{3}(d)$ with $T, \lambda$ fixed and continuous change of cell thickness. The liquid crystal cell is wedge-like, with plane confining covers forming a wedge. Such measurements can be called variable thickness interferometry (VThI). The interference field is not homogeneous and is visible in transmitted light as a system of narrow bright fringes alternating with broad dark ones parallel to wedge apex border or in reflected light as a system of narrow dark fringes alternating with broad bright ones parallel to wedge apex border (as illustrated in Fig. 4). If the twowave approximation is acceptable (as for small reflection coefficient — see Appendix), the Fizeau fringes [47] of the same width are observed as dependent of local difference of optical path - bright ones for $d \Delta n=k \lambda$ and dark ones for $d \Delta n=\frac{1}{2}(2 k-1) \lambda, k=1,2,3, \ldots$ [48]. In the literature several methods for determining $n_{o}, n_{e}$, $\Delta n$ are proposed. These ones which were applied for real materials are briefly described below, identified with the names of first authors.
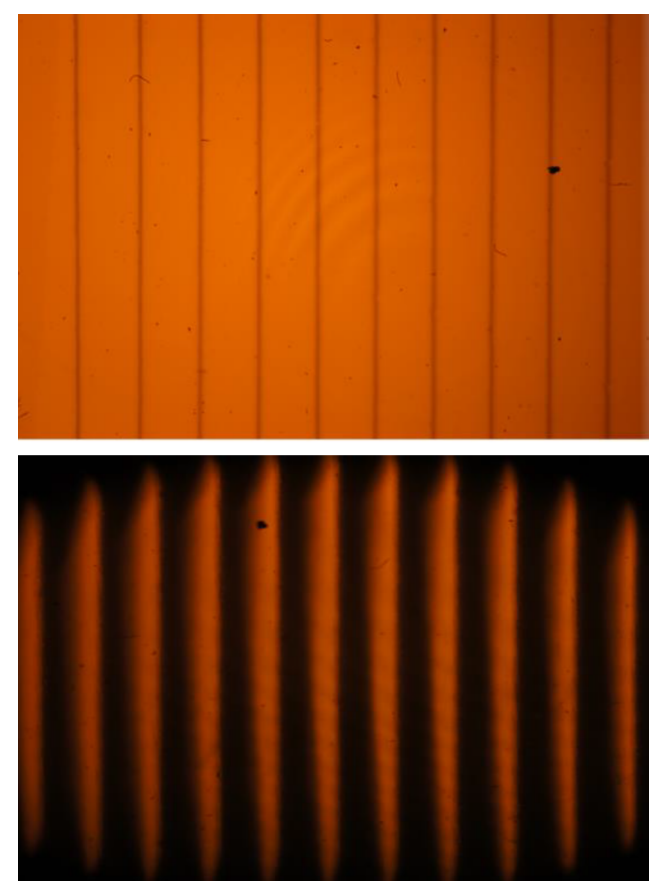

Fig. 4. Interference fringes from an empty wedge cell recorded in reflection (epi) mode (top) and transmission (dia) mode (bottom) when reflectance is around 0.80 (finesse around 80).

Method 1 (Balzarini [49]; VTI). The relative change of $\Delta n$ as a function of temperature is derived from measured $I=f_{1}(T)$. At least one independent value of $\Delta n$ must be determined by another method to find whole characteristic of $\Delta n(T)$.

Method 2 (Chang [50-53]; VWI). Wavelengths of incident light are changed. If a local minimum of intensity is observed for some $d \Delta n\left(\lambda_{1}\right)=k \lambda_{1}$, then by diminishing $\lambda$ one finds next minimum for $d \Delta n\left(\lambda_{2}\right)=(k+1) \lambda_{2}$. In this way relative changes of $\Delta n$ with $\lambda$ can be derived from measured $I=f_{2}(\lambda)$, but at least one independent measurement of $\Delta n$ together with corresponding $\lambda$ is needed for determining whole characteristic of $\Delta n(\lambda)$. If $d \Delta n \leq 0.4 \mu \mathrm{m}$, first interference fringe is observed in visible light and can be easily identified, but if $d \Delta n \geq 0.6 \mu \mathrm{m}$, it appears in infrared and is difficult to be identified [54]. 
Method 3 (Haller [55-57]; VThI). A wedge liquid crystal cell with apex angle around $1^{\circ} \div 2^{\circ}$ is used. Absolute value of $\Delta n$ can be determined in transmission mode with possible observation of texture.

Method 4 (Kuczyński et al. [58, 59]; VWI). Planeparallel cell with homogeneously aligned liquid crystal is used to determine $\Delta n$ from interference observation in transmission mode.

Method 5 exploiting Newton's rings (VThI): (a) in the transmission mode $\Delta n$ is determined (Kuczyński et al. [60-62]); (b) in the reflection mode $n_{o}$ and $n_{e}$ are determined (Chatelain [63]).

Method 6 (Opara [64, 65]; VWI) Plane-parallel cell with homogeneously aligned liquid crystal is used with special procedure for identifying interference fringes. Texture may not be observed.

Method 7 (Hanson and Shen [66]; VThI). This method unifies in one measurement system the interference method by Haller and prismatic method by Chatelain.

In all these methods (1.-7.) the observation of interference fringes or identification of their orders (in VWI) is difficult. To improve efficiency of measurements and overcome most disadvantages of above mentioned methods another technique was proposed [67-73] using cells with fringe finesse around 80 (corresponding to reflectance around 0.80 - Fig. 4 and Fig. 5). Then complementary interference method (CIM) was elaborated to avoid preparing special cell covers with so large reflection index.

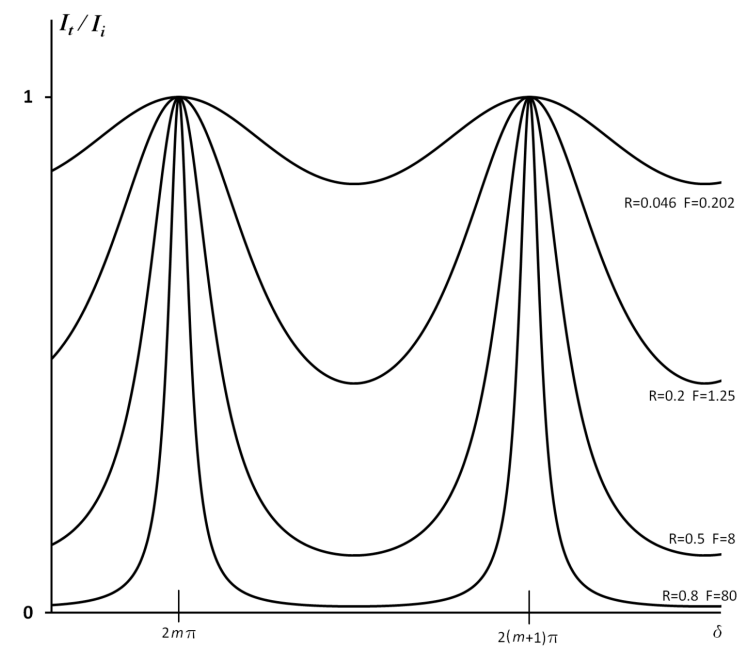

Fig. 5. Intensity of light (interference fringes of equal inclination) in transmission mode as a function of phase difference, parametrised with reflectance and fringe finesse.
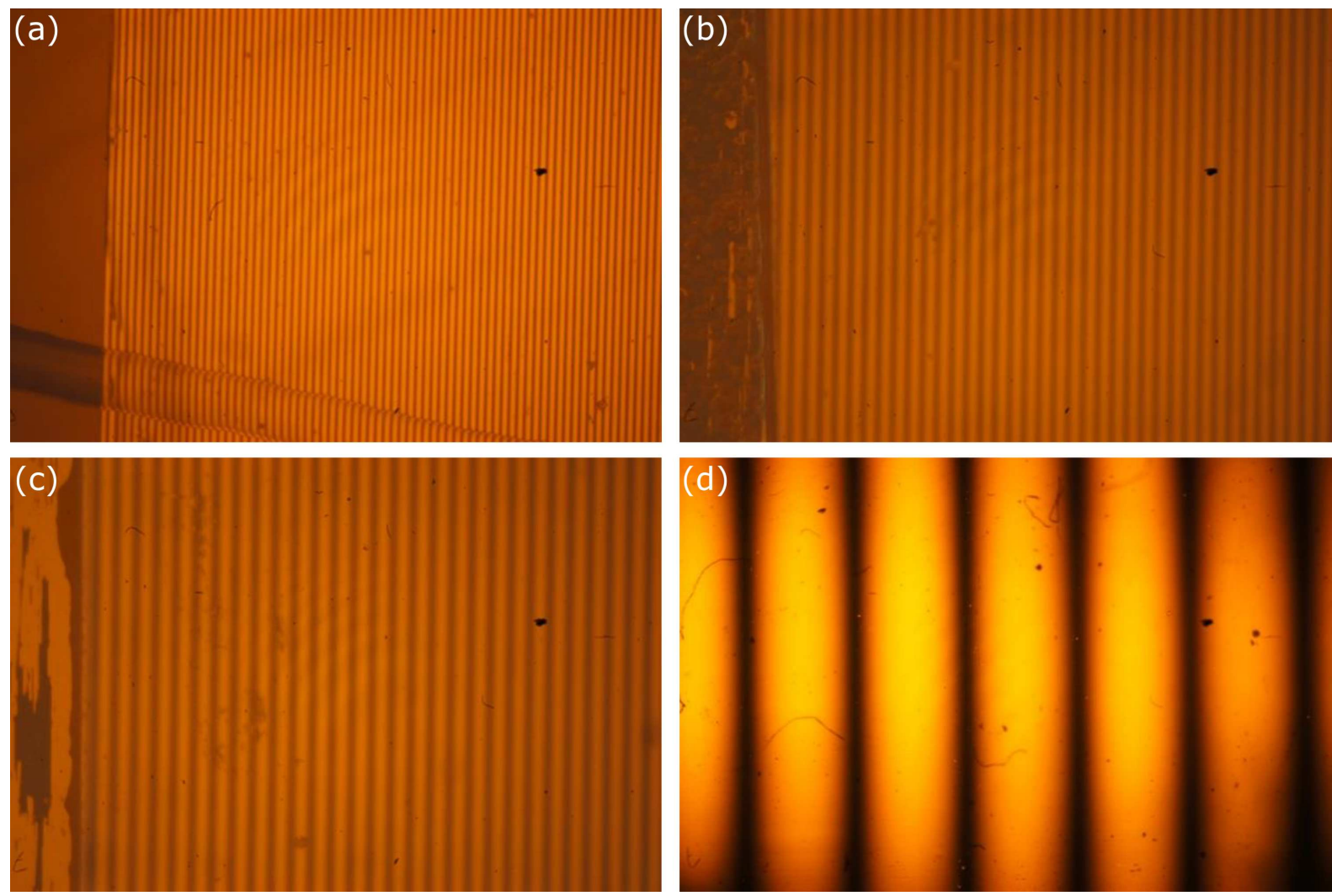

Fig. 6. Interference fringes from a wedge cell filled with nematic mixture W2016 [78, 79] recorded in reflection mode (with inter-fringes distances) for (a) $n_{e}-\Delta x_{e}$, (b) $n_{o}-\Delta x_{o}$, (c) empty cell $-\Delta x_{c}$ and in transmission mode for (d) $\Delta n$ - $\Delta x_{b}$; refractive indices are computed from corresponding distances between subsequent fringes: $n_{e}=\Delta x_{c} / \Delta x_{e}$, $n_{o}=\Delta x_{c} / \Delta x_{o}, \Delta n=2 \Delta x_{c} / \Delta x_{b}$. 
Method 8 (complementary interference method [74-79]; VThI). A wedge cell confined by slightly inclined transparent planar covers with small apex angle (of several milliradians), filled with a nematic liquid crystal aligned uniformly with the director field parallel to both apex edge and covers, is used. The interference fringes, produced in polariscope from a cell placed between analyser and polariser of transmission axes parallel or perpendicular or crossed at half-right angle to liquid crystal director field and illuminated by a normally incident non-polarised monochromatic light, are observed in both complementary reflection and transmission modes. The determination of $n_{o}, n_{e}$, and $\Delta n$ is reduced to measurements of distances between approximately equidistant fringes in both empty and filled cell and simple computations. Illustrative examples are given in Fig. 6. To obtain well-visible, almost equidistant interference fringes with approximately the same full-width-at-half-maximum-intensity (corresponding to two-wave interference, as described in Appendix and illustrated in Figs. 4 and 6) a pure monochromatic light from non-laser source and small wedge apex angle should be applied. Moreover, a material of covers (quartz, glass, or glass coated with indium-tin oxide film) together with the thickness of a spacer on shorter edge of a cell (producing inclination of covers) can be combined to improve observations for a specific liquid crystal (in experiments the plane-parallel cover plates of dimensions $1.5 \mathrm{~mm} \times 35 \mathrm{~mm} \times 22 \mathrm{~mm}$ with spacers of $(40 \div 80) \mu \mathrm{m}$ or $(300 \div 500) \mu \mathrm{m}$ for glass were used $)$.

\section{Conclusion}

Physical and some technical aspects of measurements of ordinary and extraordinary indices of samples of uniaxial liquid crystals were briefly discussed. Only the methods of experimental importance were described and commented to explaining similarities and differences. The details were omitted and replaced by references to basic works.

\section{Appendix. Airy's formulae}

The interference of a parallel beam of monochromatic light passing through a flat-parallel glass plate Fabry-Perot's interferometer (or a layer of homogeneously aligned nematic liquid crystal) can be imagined as resulting from multiple reflection and transmission of parallel rays [80] with phase difference between neighbouring rays equal to

$$
\delta=\frac{4 \pi}{\lambda} d n \cos \vartheta \text {. }
$$

The resulting light intensity is distributed according to Airy's formulae [47, 78-81]:

$I_{r}=\frac{4 R \sin ^{2}\left(\frac{1}{2} \delta\right)}{(1-R)^{2}+4 R \sin ^{2}\left(\frac{1}{2} \delta\right)} I_{i}=\frac{F \sin ^{2}\left(\frac{1}{2} \delta\right)}{1+F \sin ^{2}\left(\frac{1}{2} \delta\right)} I_{i}$

for reflected beam and

$$
I_{t}=\frac{T^{2}}{(1-R)^{2}+4 R \sin ^{2}\left(\frac{1}{2} \delta\right)} I_{i}=\frac{1}{1+F \sin ^{2}\left(\frac{1}{2} \delta\right)} I_{i}
$$

for transmitted beam, where fractions of the transmitted and reflected light intensities are related by $T+R=1$ with corresponding coefficients of transmission and reflection at surfaces of dielectric covers and filling boundary (with no absorption assumed both at the surfaces and inside the cell), $F=\frac{4 R}{(1-R)^{2}}$ is Fabry's coefficient of finesse and $\delta$ is the difference of optical paths between interfering light rays. Maxima of reflection fringes and minima of transmission fringes of equal inclination appear when $\sin ^{2}\left(\frac{1}{2} \delta\right)=1$ and the phase difference is a half-integral multiple of $\pi$,

$$
\frac{1}{2} \delta=\frac{2 \pi d n}{\lambda}=m \pi-\frac{1}{2} \pi, \quad m=1,2,3, \ldots,
$$

where $d$ is the cell thickness in the $m$ fringe position, $n$ is the refractive index and $\lambda$ is the light wavelength (Fig. 5). For normally incident light only a homogeneous interference field is observed in each plane parallel to the plate. The fringes of reflection or transition can be observed in focus of lens placed on proper side of the plate [80]. In this description the travel of light through symmetric cell covers is omitted as it does not influence resulting image.

A wedge cell with plane surfaces inclined at a small apex angle $\alpha$ to one another $(\alpha<0.01 \mathrm{rad})$, can be interpreted as a system of plane-parallel plates of different thicknesses, to that Eqs. (6), (7) apply. Since the local plate thickness $d$ now relates the distance $s$ from the wedge apex edge by the formula $d=s \tan \alpha \approx s \alpha$, Eq. (8) can be written in the equivalent form

$$
\frac{2 \pi s \alpha n}{\lambda}=m \pi-\frac{1}{2} \pi, \quad m=1,2,3, \ldots
$$

In relation to the intensity of normally incident light beam, the maxima and minima of reflected and transmitted light are

$$
\begin{aligned}
& I_{r}^{\max }=\frac{F}{1+F} I_{i}, \quad I_{r}^{\min }=0, \\
& I_{t}^{\max }=I_{i}, \quad I_{t}^{\min }=\frac{1}{1+F} I_{i} .
\end{aligned}
$$

When a wedge cell is confined by glass plates and filled with a liquid crystal, the reflection coefficient and fringe finesse are small and thus the interference fringes in transmitted light may not be observed in practice while in reflected light they are always well visible (with intensities varying always from maximum to zero minimum), as it follows from (10). In a birefringent system, when light passes through a liquid crystal cell between a polariser and an analyser with perpendicular optical axes forming half-right angles with the uniformly oriented director field, the transmitted light intensity with sharp interference fringes follows the formula:

$$
I_{t}=T I_{i} \sin ^{2}\left(\frac{\pi}{\lambda} d \Delta n\right),
$$

and is maximal when

$$
\frac{\pi s \alpha \Delta n}{\lambda}=m \pi-\frac{1}{2} \pi, \quad m=1,2,3, \ldots
$$

Equations (9), (11) are accurate in a small vicinity of wedge apex - first several tens of interference fringes there are equidistant $[74,77,78]$. 


\section{References}

[1] A. Adamczyk, "Liquid crystals", in: Encyclopedia of Modern Physics, PWN, Warszawa 1983, p. 489 (in Polish).

[2] A. Adamczyk, Z. Strugalski, Liquid Crystals, WNT, Warszawa 1976 (in Polish).

[3] A. Adamczyk, Fizyka Dielektryków i Radiospektroskopia XI, 241 (1979) (in Polish).

[4] J. Żmija, J. Zieliński, J. Parka, E. NowinowskiKruszelnicki, Liquid Crystal Displays - Physics, Technology, Application, PWN, Warszawa 1993 (in Polish).

[5] W.A. Wooster, Experimental Crystal Physics, Oxford 1957.

[6] T. Hanc, Optical Measurements, WNT, Warszawa 1964 (in Polish).

[7] F. Kohlrausch, Practical Physics, Teubner, Stuttgart 1955 (in German).

[8] J.R. Meyer-Arendt, Introduction to Classical and Modern Optics, Prentice-Hall, Englewood Cliffs (NJ) 1972

[9] S. Pieńkowski, Experimental Physics, Vol. III, Optics, PWN, Warszawa 1955 (in Polish).

[10] M. Grotowski, Optics, ŁTN, Łódź 1954 (in Polish).

[11] S. Szczeniowski, Experimental Physics, Part IV, Optics, PWN, Warszawa 1963 (in Polish).

[12] F.E. Dorn, Phys. Z. 11, 777 (1910).

[13] G. Pelzl, H. Sackmann, Mol. Cryst. Liq. Cryst. 15, 75 (1971)

[14] F. Stumpf, Ann. Phys. 37, 351 (1912).

[15] V.W. Kreide, Phys. Z. 14, 979 (1913).

[16] L. Kopf, J. Opt. Soc. Am. 58, 269 (1968).

[17] A.K. Zeminder, S. Paul, R. Paul, Mol. Cryst. Liq. Cryst. 61, 191 (1980).

[18] J.W. Baran, F. Borowski, J. Kędzierski, Z. Raszewski, J. Żmija, K.W. Sadowska, Bull. Pol. Acad. Sci. 26, 117 (1978).

[19] G. Pelzl, H. Sackmann, Z. Phys. Chem. 254, 354 (1973).

[20] G. Pelzl, R. Retting, D. Demus, Z. Phys. Chem. 256 305 (1975).

[21] P. Adamski, A. Dylik-Gromiec, Mol. Cryst. Liq. Cryst. 25, 281 (1974).

[22] P. Adamski, A. Dylik-Gromiec, Mol. Cryst. Liq. Cryst. 35, 337 (1976).

[23] P. Adamski, A. Dylik-Gromiec, Mol. Cryst. Liq. Cryst. 25, 273, (1974).

[24] P. Adamski, A. Dylik-Gromiec, Zeszyty Naukowe Politechniki Łódzkiej - Fizyka, issue 5, no. 308, Łódź 1979 (in Polish).

[25] M. Roushdy, Mol. Cryst. Liq. Cryst. 457, 151 (2006).

[26] F. Hodam, Formulae and Tables of Technical Optics, Verlag Technik, Berlin 1974 (in German).

[27] P. Chatelain, C.R. Acad. Sci. Paris 203, 266 (1936).

[28] P. Chatelain, C.R. Acad. Sci. Paris 203, 1169 (1936).

[29] M. Brunet-Germain, C.R. Acad. Sci. Paris 271, 1075 (1970).
[30] P. Chatelain, Bull. Soc. Franc. Min. Cryst. 78, 262 (1955).

[31] P. Chatelain, M. Germain, C.R. Acad. Sci. Paris 259, 127 (1964)

[32] P. Chatelain, Bull. Soc. Franc. Min. Cryst. 66, 105 (1943).

[33] O. Pellet, P. Chatelain, Bull. Soc. Franc. Min. Cryst. 73, 154 (1950).

[34] D.V. Rao, P. Pardhasaradhi, V.G.K.M. Pisipati, P.V.D. Prasad, Phase Transit. 88, 137 (2015).

[35] M.V.R.K. Murty, R.P. Shukla, Opt. Eng. 18, 177 (1979).

[36] P.G.D. Gennes, J. Prost, The Physics of Liquid Crystals, 2nd ed., Clarendon Press, Oxford 1993.

[37] R.G. Horn, J. Phys. 39, 105 (1978).

[38] N.V. Madhusudana, R. Shashidhar, S. Chandrasekhar, Mol. Cryst. Liq. Cryst. 13, 61 (1971).

[39] H. Mada, S. Kobayashi, Mol. Cryst. Liq. Cryst. 33, 147 (1976).

[40] T. Penkala, Crystal Optics, PWN, Warszawa 1971 (in Polish).

[41] F. Ratajczyk, Optics of Anisotropic Centers, PWN, Warszawa 1994 (in Polish).

[42] J. Chojnacki, Chemical and Physical Crystallography, PWN, Warszawa 1961 (in Polish).

[43] M. Pluta, Advanced Light Microscopy, Vol. I (Principles and Basic Properties), Vol. II (Specialized Methods), Vol. III (Measuring Techniques), PWN, Warszawa 1988-1989-1993.

[44] M. Pluta, Microinterferometry in Polarized Light, WNT, Warszawa 1991 (in Polish).

[45] M. Born, E. Wolf, Principles of Optics. Electromagnetic Theory of Propagation, Interference and Diffraction of Light, Cambridge Univ. Press, London 2003.

[46] M. Pluta, Appl. Opt. 28, 1453 (1989).

[47] M. Pluta, Optical Microscopy, PWN, Warszawa 1982 (in Polish).

[48] J.W. Baran, J. Kędzierski, Z. Raszewski, J. Żmija, Electron. Mater. 2, 7 (1978) (in Polish).

[49] D.A. Balzarini, Phys. Rev. Lett. 25, 914 (1970).

[50] R. Chang, Mater. Res. Bull. 7, 267 (1972).

[51] R. Chang, Mol. Cryst. Liq. Cryst. 28, 1 (1974).

[52] R. Chang, Mol. Cryst. Liq. Cryst. 30, 155 (1975).

[53] R. Chang, Mol. Cryst. Liq. Cryst. 34, 65 (1976).

[54] Z. Raszewski, E. Nowinowski-Kruszelnicki, J. Kędzierski, P. Perkowski, W. Piecek, R. Dąbrowski, P. Morawiak, K. Ogrodnik, Mol. Cryst. Liq. Cryst. 525, 112 (2010).

[55] I. Haller, H.A. Huggins, M.J. Freiser, Mol. Cryst. Liq. Cryst. 16, 53 (1972).

[56] I. Haller, N.A. Huggins, H.R. Lilienthal, T.R. McGuire, J. Phys. Chem. 77, 950 (1973).

[57] J.W. Baran, J. Kędzierski, Z. Raszewski, J. Żmija, Biuletyn WAT 25, 147 (1976) (in Polish).

[58] W. Kuczyński, B. Stryła, Mol. Cryst. Liq. Cryst. 31, 267 (1975). 
[59] W. Kuczyński, P. Pierański, K. Wojciechowski, B. Stryła, Mol. Cryst. Liq. Cryst. 34, 203 (1977).

[60] B. Żywucki, W. Kuczyński, G. Czechowski, Proc. SPIE 2372, 151 (1995).

[61] B. Żywucki, W. Kuczyński, IEEE Trans. Diel. Electr. Insul. 8, 512 (2001).

[62] W. Kuczyński, B. Żywucki, J. Małecki, Mol. Cryst. Liq. Cryst. 381, 1 (2002).

[63] P. Chatelain, Bull. Soc. Franc. Min. Cryst. 60, 280 (1937)

[64] T. Opara, Ph.D. Thesis, WAT, Warszawa 1982.

[65] T. Opara, J.W. Baran, J. Kędzierski, J. Żmija, Biul. WAT 35, 21 (1986) (in Polish).

[66] E.G. Hanson, Y.R. Shen, Mol. Cryst. Liq. Cryst. 36, 193 (1976).

[67] Z. Raszewski, W. Piecek, L.R. Jaroszewicz, R. Dabrowski, E. Nowinowski-Kruszelnicki, L. Soms, M. Olifierczuk, J. Kędzierski, P. Morawiak, R. Mazur, E. Miszczyk, M. Mrukiewicz, K. Kowiorski, OptoElectron. Rev. 22, 196 (2014).

[68] Z. Raszewski, W. Piecek, L.R. Jaroszewicz, E. Nowinowski-Kruszelnicki, P. Perkowski, L. Soms, R. Dąbrowski, J. Kędzierski, M. Olifierczuk, M. Mrukiewicz, E. Miszczyk, P. Morawiak, R. Mazur, K. Kowiorski, Adv. Mater. Res. 909, 12 (2014).

[69] W. Piecek, L.R. Jaroszewicz, E. Miszczyk, Z. Raszewski, M. Mrukiewicz, P. Perkowski, E. Nowinowski-Kruszelnicki, J. Zieliński, M. Olifierczuk, J. Kędzierski, X. W.Sun, K. Garbat, K. Kowiorski, P. Morawiak, R. Mazur, J. Tkaczyk, Opto-Electron. Rev. 24, 169 (2016).

[70] W. Piecek, L.R. Jaroszewicz, E. Miszczyk, Z. Raszewski, M. Mrukiewicz, P. Kula, K. Jasek, P. Perkowski, E. Nowinowski-Kruszelnicki, J. Zieliński, J. Kedzierski, M. Olifierczuk, U. Chodorow, P. Morawiak, R. Mazur, K. Kowiorski, P. Harmata, J. Herman, Opto-Electron. Rev. 25, 103 (2017).
[71] E. Miszczyk, R. Mazur, P. Morawiak, M. Mrukiewicz, W. Piecek, Z. Raszewski, P. Kula, K. Kowiorski, J. Kędzierski, J. Zieliński, Liq. Cryst. 45, 1690 (2018).

[72] E. Miszczyk, P. Morawiak, R. Mazur, M. Mrukiewicz, M. Olifierczuk, W. Piecek, Z. Raszewski, P. Kula, J. Kędzierski, J. Zieliński, P. Harmata Liq. Cryst. 45, 703 (2017).

[73] E. Miszczyk, Z. Raszewski, J. Kędzierski, E. Nowinowski-Kruszelnicki, M.A. Kojdecki, P. Perkowski, W. Piecek, M. Olifierczuk, Mol. Cryst. Liq. Cryst. 544, 22 (2011).

[74] J. Kędzierski, Z. Raszewski, M.A. Kojdecki, E. Kruszelnicki-Nowinowski, P. Perkowski, W. Piecek, E. Miszczyk, J. Zielinski, P. Morawiak, K. Ogrodnik, Opto-Electron. Rev. 18, 214 (2010).

[75] K. Kowiorski, J. Kędzierski, Z. Raszewski, M.A. Kojdecki, J. Herman, E. Miszczyk, W. Piecek, Acta Phys. Pol. A 124, 946 (2013).

[76] J. Kędzierski, K. Garbat, Z. Raszewski, M.A. Kojdecki, K. Kowiorski, L.R. Jaroszewicz, E. Miszczyk, R. Dabrowski, J. Zieliński, W. Piecek, Opto-Electron. Rev. 22, 162 (2014)

[77] K. Kowiorski, J. Kędzierski, Z. Raszewski, M. Chrunik, W. Piecek, M.A. Kojdecki, A. Chlanda, J. Herman, E. Miszczyk, Innovat. Manufact. Techol. 59, (2013) (in Polish).

[78] K. Kowiorski, J. Kędzierski, Z. Raszewski, M.A. Kojdecki, O. Chojnowska, K. Garbat, E. Miszczyk, W. Piecek, Phase Transit. 89, 403 (2016).

[79] K. Kowiorski, Ph.D. Thesis, WAT, 2016.

[80] S. Tolansky, Multiple-Beam Interferometry Microscopy, London 1948.

[81] G.B. Airy, On the Undulatory Theory of Optics, Macmillan and Co, London 1866. 